\title{
Subcutaneous tubercular cold abscess: Uncommon presentation of a common disease
}

\author{
*Sanghamitra Ray ${ }^{1}$, Rajesh Kumar Meena ${ }^{2}$, Prakash Chand Jain
}

Sri Lanka Journal of Child Health, 2018; 47: 276-278

DOI: http://dx.doi.org/10.4038/sljch.v47i3.8554

(Keywords: Tuberculosis, cold abscess, paediatric, primary cold abscess)

\section{Case report}

A 14 year old girl presented to our out-patient department with a complaint of swelling in the right side of the lower para-spinal area which was gradually increasing for the last six weeks. There was no history of fever or any other systemic features. She was well built with a weight of $43 \mathrm{~kg}$ and a height of $153 \mathrm{~cm}$ (body mass index 18.3). There was

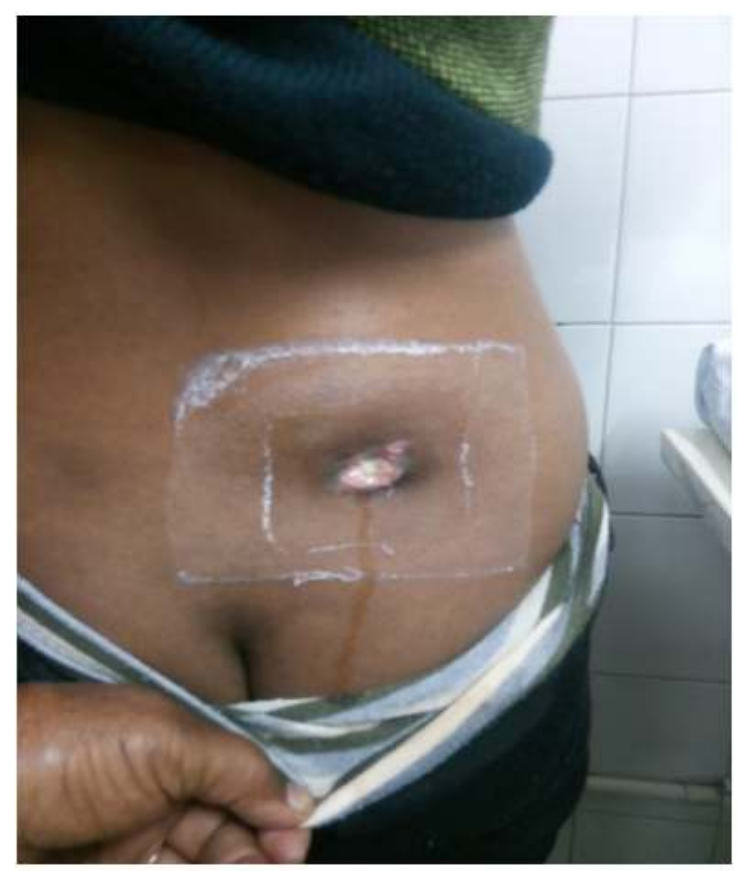

Figure 1: Tubercular cold abscess with discharging sinus

${ }^{1}$ Cantonment General Hospital, India, ${ }^{2}$ ESIC Hospital, Rohini, India

*Correspondence: dr.sanghamitra.ray@gmail.com (Received on 07 February 2017: Accepted after revision on 17 March @017)

The authors declare that there are no conflicts of interest

Personal funding was used for the project.

Open Access Article published under the Creative

Commons Attribution CC-BY

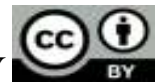

no significant past history. Local examination showed a fluctuant, non-pulsatile swelling measuring $10 \mathrm{~cm} \times 14 \mathrm{~cm}$, local temperature not raised, nontender and in the subcutaneous plane not fixed to underlying structures (Figure 1).

There was no regional lymphadenopathy and the systemic examination was unremarkable. There was no local spinal or adjacent hip joint tenderness. She had received 2 courses of antibiotics before coming to our facility. She had no history of repeated infections. A provisional diagnosis of antibioma or chronic abscess was made. Ultrasonography (USG) showed two adjacent hypoechoic areas measuring 8.2 $\mathrm{cm} \times 3.5 \mathrm{~cm} \times 7.1 \mathrm{~cm}$ (volume - 107.3cc) and $4.2 \mathrm{~cm}$ x $3.1 \mathrm{~cm} \mathrm{x} 4.0 \mathrm{~cm}$ (volume - 28.2cc) respectively (Figure 2).

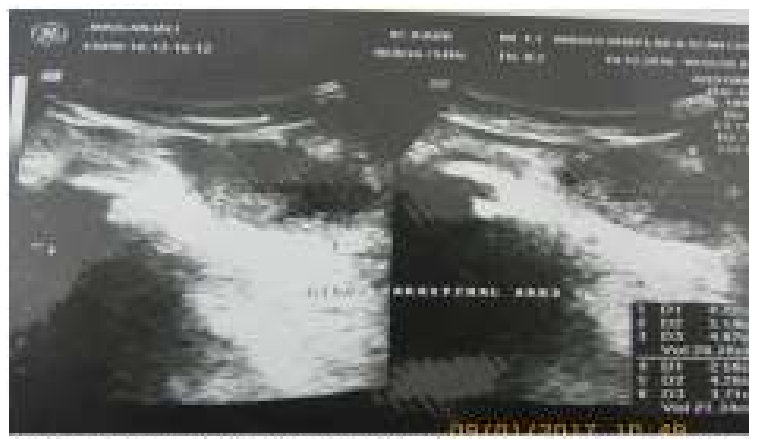

Fipure 2: Eltrasonogrupliy findings dopicting subcutaneous abscess

Tubercular cold abscess had to be excluded due its epidemiological importance. Fine needle aspiration cytology (FNAC) of the swelling showed a granuloma suggestive of tuberculosis but staining for acid fast bacilli was negative and culture for mycobacterium was also negative. As no source of tuberculosis was found, pus from the abscess was sent for gene Xpert real time PCR which confirmed the presence of rifampicin sensitive mycobacterium tuberculosis. She had no history of contact with tuberculosis. X-rays of hip joints, thigh and spine were done but showed no bony abnormalities or evidence of chronic osteomyelitis (Figure 3). 


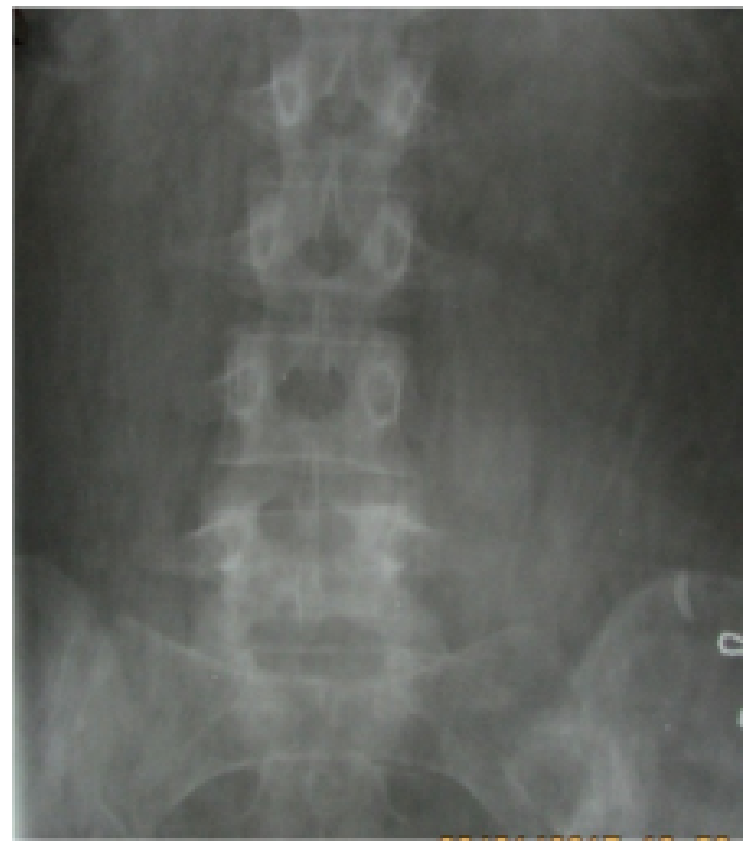

Figure 3: X-ray of spine

On further detailed investigations, chest X-ray (Figure 4), gastric aspirate for AFB, erythrocyte sedimentation rate, and ultrasound of abdomen were done but no evidence of tuberculosis at any other site was found.

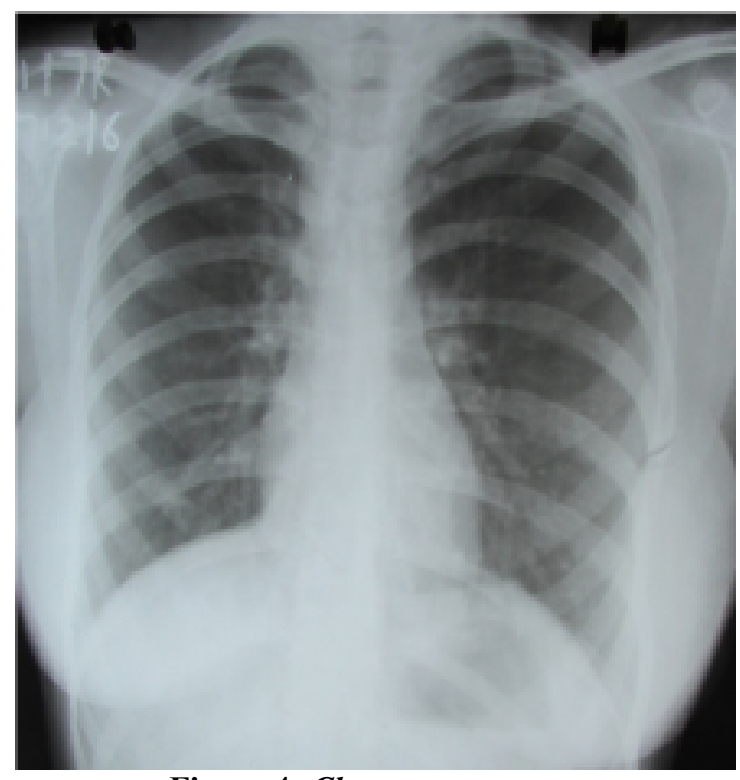

Figure 4: Chest $x$-ray

Contact screening of caregivers was also noncontributory. Child had received Bacillus-CalmetteGuérin (BCG) vaccination at birth (mark present on left shoulder) and Mantoux test was positive measuring $15 \mathrm{~mm}$. She was non-reactive for human immunodeficiency virus (HIV). On follow up, the abscess spontaneously ruptured and a sinus was formed. She was started on anti-tubercular therapy under DOTS (Directly Observed Treatment, Short Course). She is currently under regular follow up. The swelling has reduced in size but still is draining pus from sinus. Frequent aseptic dressing is being done on follow up.

\section{Discussion}

Tubercular cold abscess is a long known entity. There have been occasional reports of cold abscess caused by mycobacterium tuberculosis at unusual sites like the sternum, breast tissue, corpus cavernosum, and tongue, mostly in adults ${ }^{1}$. Otherwise, isolated subcutaneous abscess without any other evidence of tuberculosis is very unusual especially in children. That is why these types of cases raise some questions regarding their pathogenesis in a healthy child as in our case. One case series from South India reported three infants with isolated primary tubercular gluteal abscess $^{2}$. Extra pulmonary manifestations of TB are less common but not rare. These can arise from the spread of infectious secretions through the gastrointestinal and respiratory tracts, contiguous spread, or lymphogenous and/or haematogenous dissemination ${ }^{3}$. Cold abscess is described as an abscess without the characteristic signs of inflammation. It may be present in immunodeficiency disorders, deep mycoses as in coccidioidomycosis, blastomycosis, nocardiosis, actinomycosis and other non-infectious diseases like intramuscular injection of clindamycin, penicillin etc ${ }^{4}$ and also in patients with hyperimmunoglobulin E syndrome ${ }^{5}$.

Confirmation of the disease requires biopsy demonstrating acid-fast bacilli on microscopy or isolated in culture of the organism. But its usefulness gets limited by the long time required for the result and chance of false negative results in pauci-bacillary disease. In contrast with pulmonary $\mathrm{TB}$, extra pulmonary TB lesions have a lower amount of bacilli, resulting in less accurate results from microscopy ${ }^{6}$. PCR has been an effective diagnostic tool for pulmonary $\mathrm{TB}$ and is now thought to have high sensitivity and specificity for extra-pulmonary TB as well. Compared to culture, PCR allows for a more rapid diagnosis and greater sensitivity even when small amounts of bacilli are present ${ }^{7}$. In our case too it helped in definitive diagnosis. But despite our sincere efforts we could not ascertain the source of infection as well as the primary lesion in this index case. We could find a similar kind of case reported from north India where an infant was diagnosed with 
primary tubercular abscess of thigh at the site of DPT injection. In this case too authors failed to delineate the cause ${ }^{8}$.

Any slowly growing swelling without any signs of inflammation and not responding to usual treatment should raise the possibility of a cold abscess and should be worked up accordingly keeping tuberculosis as a strong possibility in tropical countries like India. Authors also feel that more of these kinds of cases need to be evaluated thoroughly to gain more on its pathogenesis.

\section{References}

1. Mohanapriya $\mathrm{T}$, Singh KB, Arulappan T, Dhanasekar. Lingual tuberculosis. Indian Journal of Tuberculosis 2012; 59(1):39-41. PMid: 22670511

2. Bennett J, Dolin R, Mandell BM. Douglas, and Bennett's Principles and Practice of Infectious Diseases, Elsevier Health Sciences, London, UK, 2014.

3. Jackson R, Stephens L, Kelly P. Cold subcutaneous abscesses. Journal of the National Medical Association 1990; 82: 733-6.

PMid: 2280425 PMCid: PMC2571557

4. Holland SM, DeLeo FR, Elloumi HZ, Hsu $\mathrm{AP}$, et al. Mutations in the hyper-IgE syndrome. New England Journal of Medicine 2007; 357 (16): 1608-19. https://doi.org/10.1056/NEJMoa073687 PMid: 17881745
5. Colmenero JD, Ruiz-Mesa JD, SanjuanJimenez R, Sobrino B, Morata P. Establishing the diagnosis of tuberculous vertebral osteomyelitis. European Spine Journal 2013; 22 (S4): S579-S586. https://doi.org/10.1007/s00586-012-2348-2 PMid: 22576157 PMCid: PMC3691410

6. Merino P, Candel FJ, Gestoso I, Baos E, Picazo J. Microbiological diagnosis of spinal tuberculosis. International Orthopaedics 2012; 36(2): 233-8. https://doi.org/10.1007/s00264-011-1461-x PMid: 22252412 PMCid: PMC3282864

7. Balasubramanian $\mathrm{S}$, Kaarthigeyan $\mathrm{K}$, Aparna V. Tuberculous gluteal abscess in infancy. Indian Pediatrics 2008; 45:862-3. PMid: 18948661

8. Mishra D, Mohta A, Arora P. Cold abscess of the thigh in an Infant. Kathmandu University Medical Journal 2013; 41(1):867. 